- All letters must be typed with double spacing and signed by all authors.

No letter should be more than 400 words.

- For letters on scientific subjects we normally reserve our correspondence columns for those relating to issues discussed recently (within six weeks) in the BMJ.

- We do not routinely acknowledge letters. Please send a stamped addressed envelope if you would like an acknowledgment.

- Because we receive many more letters than we can publish we may shorten those we do print, particularly when we receive several on the same subject.

\section{Tuberculosis in Britain}

SIR, - The British Thoracic Society's report for the control and prevention of tuberculosis in Britain referring to protection of NHS employees makes recommendations which have been awaited a long time.'

It is generally agreed that far too many routine chest radiographs are performed on NHS employees. Yet the report suggests that grade 2 reactions to Heaf testing in the absence of previous BCG should be regarded as similar to grades 3 or 4 and that chest radiography should be performed to decide if further action is needed.

I analysed the results of 1424 tuberculin tests on prospective NHS staff in 12 of the 19 districts in North Western region over three months (table). Most of those tested were young student nurses, and few had an unequivocal history of previous BCG. When these tests were carried out it was still policy to examine all staff by chest radiography and in this group no cases of tuberculosis were found.

Heaf test reactions in 1424 prospective NHS staff in 12 districts in North Western region

\begin{tabular}{cc}
\hline Heaf test grade & No $(\%)$ of staff $(n=1424)$ \\
\hline 0 & $235(16)$ \\
1 & $211(15)$ \\
2 & $461(32)$ \\
3 & $365(26)$ \\
4 & $152(11)$ \\
\hline
\end{tabular}

The new recommendations would require almost $70 \%$ of these staff to have chest radiography. Do we really want to continue to subject two thirds of our staff to radiography?

M S GATLEY

Occupational Health Department,

North Manchester General Hospital.

Manchester M8 6RB

1 Subcommittee of the Joint Tuberculosis Committee of the British Thoracic Society. Control and prevention of tuberculosis in Britain: an updated code of practice. Br.Med f 1990;300:995-9. (14 April.)

SIR, - We welcome the updated code of practice compiled by the sub-committee of the British Thoracic Society's Joint 'Tuberculosis Committee.' In particular we are grateful for the reminder that tuberculosis, whether infectious or not, is a notifiable disease, and we applaud the emphasis made on the importance of contact tracing with the need for adequate support by clerical staff and trained health visitors.

The guidance on examining close contacts of tuberculosis includes a warning that a "negative test result in immunosuppressed subjects does not exclude tuberculosis infection." This is timely advice; in view of the current gradual increase in the incidence of HIV infection low or absent tuberculin hypersensitivity must be interpreted with caution because infected subjects become immunologically compromised and no longer react to the tuberculin skin test. The physician in charge of contact screening is usually unaware of the HIV state of the index case and relevant contacts.

We would, however, like to add cautionary notes on the following issues.

Close contacts of tuberculosis should have a repeat tuberculin test at six weeks, if they have had previous BCG vaccination and are initially negative or weak reactors, to exclude subsequently increasing tuberculin hypersensitivity due to superinfection with Mycobacterium tuberculosis. Such patients have developed tuberculous lesions within a year of follow up.

In NHS employees with strongly positive tuberculin reactions, irrespective of previous BCG vaccination or ethnic group, repeat chest radiography is recommended in three months to exclude developing disease. ${ }^{2}$ In the absence of previous BCG vaccination a Grade I reaction to the multipuncture (Heaf or tine) tuberculin test is strong evidence of adequate protection. ${ }^{+}$'In such cases we feel BCG vaccination may safely be withheld from NHS staff. If BCG is given it may produce large ulcers. ${ }^{\circ}$ We would allow these subjects to work in a high risk area.

It is helpful for NHS employees to have preemployment chest radiography, not only for early detection of pulmonary tuberculosis but also to provide a baseline in the event of subsequent pulmonary disease. For those working in a normal risk area we agree that periodic chest radiography is unnecessary, but it may be advisable at the termination of employment in the health service in view of current industrial injuries legislation. On the other hand, we advise that chest radiography is performed annually for staff at high risk in laboratories and every two years for other staff working in high risk areas. This is the practice in our hospitals. FREDA FESTENSTEIN D W EMPEY R M RUDD

London Chest Hospital,

London E2 9JX

1 Subcommittee of the Joint Tuberculosis Committee of the British Thoracic Society. Control and prevention of tuberculosis in Britain: an updated code of practice. Br.Med 7 1990;300:995-9. Britain: an
(14 April.)

2 Festenstein F. Spread of tuberculosis within a family. Lancet $1981 ;$ i:603-5.

3 Festenstein F. Tuberculosis in hospital doctors. Br Med $\mathrm{J}$ $1984 ; 289: 1327-8$

+ Caplin M. The tuberculin test in clinical practice. London: Baillière Tindall, 1980

Fine PEM, Redrigues LC. Modern vaccines: mycobacterial diseases. Lancet 1990;335: 1016-20

6 Newham Health Department, London. BCG vaccination of tuberculin-positive (Heaf-test Grade 1) children. Lancet 1969 ;ii:537-9.

7 Department of Health and Social Security. The Social Security (Industrial Injuries) (Prescribed Diseases) Amendment (No 2) Regulations 1983. London: HMSO, 1983.

\section{Decision making in medical emergencies}

SIR, - We wholeheartedly endorse the suggestion from $\operatorname{Dr} G$ Hartnell that inexperienced junior doctors should not have to make important decisions about treatment in acute medical emergencies.' Inappropriate use of streptokinase in aortic dissection unrecognised on chest radiography is one example among many.

Dr Hartnell's suggestion that medical registrars should be making these decisions rather than house officers is, however, seldom possible in district general hospitals such as ours where one medical registrar and six consultant physicians are responsible for acute medical admissions. We have no medical senior registrars. This contrasts with Dr Hartnell's own hospital, also within our region, where there are 13 medical registrars and eight medical senior registrars.

As our district's representatives on the regional medical specialist training committee and the regional manpower committee we welcomed the recent attempt by our region to redress this imbalance and redistribute the medical registrar posts. There has, however, been considerable resistance to this proposal from hospitals that have the luxury of sufficient staff in the middle grades.

We would encourage Dr Hartnell to persuade his physician colleagues that the quality of care he advocates should be adopted universally and not just at large teaching hospitals.

RICHARD A BANKS JOHN PRIOR

Gloucestershire Royal Hospital

Gloucester GLI 3NN

1 Hartnell (3. Streptokinase in acute aortic dissection. Br Med J 1990;300:941. (7 April.)

\section{Genital warts}

SIR, - I was dismayed to read $\mathrm{Mr}$ Malcolm Griffiths's letter calling for a stop to the "wasteful overscreening" of women with genital warts. ${ }^{\prime} \mathrm{He}$ refers, of course, to the widespread practice of recommending that women with genital warts have access to more frequent cytological screening.

$\mathrm{Mr}$ Griffiths states that there is no reason to anticipate an association between genital warts and cervical cancer because, although the human papillomavirus causes genital warts and has been implicated in the aetiology of cervical cancer, the type of human papillomavirus differs in each case (types 6 and 11 in genital warts, types 16 and 18 in cervical cancer).

Schneider et al studied women with a history of abnormal Papanicolaou smears and tested for human papillomavirus types $6,11,16$, and 18 to 
determine the viruses' oncogenic potential.: Of 24 women in whom only human papillomavirus types 16 and 18 were detected, five progressed to cervical intraepithelial neoplasia grade III compared with none of the 12 women with only types 6 and 11 , confirming previous studies. 'Particularly interesting, however, were the 41 women who had clinical evidence of condylomata acuminata of the vulva or the perineum, or both. Human papillomavirus types 6 and 11 were identified using the in situ hybridisation test and were isolated from the cervix in 33 cases, either alone (in 25 cases) or combined with human papillomavirus types 16 and 18 (in eight cases). In a further eight cases cervical cells were positive for human papillomavirus types 16 and 18 alone.

It is this observation, that human papillomavirus types 6 and 11 and types 16 and 18 may coexist, which is so important. Indeed, it has even been suggested that types 6 and 11 may act as helper viruses for types 16 and 18 .

We have no simple or generally available method of screening specifically for human papillomavirus types 16 and 18 . We must, therefore, rely on clinical indicators of risk. I would suggest that the presence of genital warts is one such indicator.

WINIFRED C STACK

Department of Genitourinary Medicine,

Newcastle General Hospital,

Newcastle-upon-Tyne NE4 6BE

1 Griffiths M. Genital warts. Br.Med J 1990;300:1013-4. (14 April.)

Schneider A SawandaE, Gissman L, Shah K. Human papillomavirus in women with a history of abnormal Papanicolaon smears and in their male partners. Obstet Gynecol 1987;69:554 62 .

3 Hawley PM. On human papillomavirus. N Engl J Med 1986;315: 1089-90.

+ Crawford L. Papillomaviruses and cervical tumours. Nature 1984:310:16.

\section{Dyspepsia in general practice}

SIR, - In their recent editorial' Dr C Brown and Dr W D W Rees have done a disservice to those who wish to see gastric cancer diagnosed early, when it can be cured. They have ignored the evidence from Japan, where endoscopy on demand, or in response to the most trivial dyspeptic symptom, has resulted in the proportion of gastric cancers that are diagnosed early rising from $10 \%$ to over $60 \%^{2}$ while in this country it remains under $10 \% .^{3}$ While the incidence of gastric cancer in the United Kingdom (.30/10 population) is much lower than that in Japan (150/10' population), gastric cancer is none the less the fourth most common malignant disease in the United Kingdom and the incidence in this country in the past decade has not fallen significantly.

The point which Drs Brown and Rees seem to have overlooked is that patients with early gastric cancer present without symptoms or with trivial symptoms which are often transient and responsive to treatment with an $\mathrm{H}_{2}$ blocker. Such patients with minor symptoms, or with symptoms cured by an $\mathrm{H}_{2}$ blocker, will rarely reattend six weeks later. These are the very patients who must be examined by endoscopy if gastric cancer is to be diagnosed early. We disagree that it is patients with weight loss and anorexia who clearly need urgent diagnosis. They show the features of late disease, and by the time weight has been lost a cure is unlikely.

Early endoscopy in patients over 40 presenting with dyspepsia has been shown clearly to increase the proportion of patients with gastric cancer diagnosed early to over $20 \%$ (J Fielding, personal communication). It was extraordinary to choose an American reference to support the statement that only $1 \%$ of all dyspeptic patients will be found to have oesophageal or gastric cancer, when the United States has one of the lowest incidences of gastric cancer in the world. Using open access endoscopy we found six patients per hundred examined to have gastro-oesophageal malignancy, and Fielding found four per hundred. This compares with a yield of about four cases per 1000 for breast cancer screening.

Only with a policy of endoscopy for each patient over 40 who presents with dyspeptic symptoms, no matter how trivial or transient, will gastric cancer become a curable disease in the United Kingdom. The revenue implications are considerable but doctors and politicians must rise to the challenge. I M C MACINTYRE D M SEDGWICK

General Surgical Unit,

Western General Hospital

Brown C, Rees WDW Dyspepsia in general practice. Br Med $f$ 1990:300:829-30. (31 March.)

2 Hisamichi S. Screening for gastric cancer. World f Surg 1989. 13:31-7.

3 De Dombal FT, Price AB, Thompson $\mathrm{H}$, et al. The British Society of Gastroenterology early gastric cancer/dysplasia survey: an interim report. Gut 1990;31:115-20.

4 Sedgwick DM, Akoh J, Clarke JA, Macintyre IMC. Gastric cancer in Scotland-a halt in the decline [Abstract]. Gut (in press)

5 Macintvre IMC. Open access endoscopy for general practitioners Practitioner 1988;232:348-51.

AUTHORS' REPLY, - We thank Mr I M C Macintyre and $\mathrm{Mr} \mathrm{D} M$ Sedgwick for their interest in our editorial' but believe that some of their sentiments are misplaced and that many of their proposals are based on inadequate data.

Results from Japanese studies on early gastric cancer may be interesting, but their relevance to disease in the United Kingdom, where the natura course of early cancer may be different, remains debatable. Lesions differ in morphology and distribution, and with similar surgical procedures the outcome of the disease is much better in Japan. ${ }^{2}$

In a recent survey of endoscopy in Birmingham Fielding reported that of $2 \%$ of dyspeptic patients with gastric cancer about $20 \%$ had early cancer. These results are slightly more optimistic than North American data ${ }^{4}$ but are quite different from Japanese results. None of the patients in Birming ham screened when under 50 had gastric cancer Even in Mr Macintyre's own study of 382 patients having "open access endoscopy" about $2 \%$ had gastric cancer. ${ }^{5}$ None of the cancers occurred in patients younger than 59 , and no cases of early cancer were detected.

A recent study in Leicester concluded that gastric cancer was rare below 45 and found that most of the younger patients with this disease over 6 years presented with "high risk" symptoms (weight loss, vomiting, anaemia, and gastrointestinal haemorrhage). ${ }^{6}$ This information is com patible with an interim report by a group from the British Society of Gastroenterology that investigated early gastric cancer and dysplasia. ${ }^{7}$ Of 132 patients with early gastric cancer, $91 \%$ were considered to be at high risk after the data were analysed by computer.

In the United Kingdom patients with trivial symptoms of dyspepsia resort to self medication and do not usually present until they have advanced disease. Mr Macintyre's and Mr Sedgwick's suggestion that all patients over 40 with trivial dyspepsia should be referred for immediate endoscopy is unrealistic. Without a campaign of public education and massive injection of funding and manpower such a policy will merely increase waiting time for endoscopy without improving the detection rate of treatable early gastric cancer. Clearer data are needed on the incidence and natural course of early gastric cancer in the United Kingdom before committing scarce resources to the mammoth task of screening dyspeptic patients on a large scale.

We regret the misguided and emotive response to our editorial by Drs $M$ A Sampson and C Record. ${ }^{8}$ Their comments are mostly irrelevant to the gist of our editorial and form a highly biased appraisal of the relative merits of endoscopy and double contrast barium meal examination.

The merits of upper gastrointestinal endoscopy in patients with dyspepsia are acknowledged widely by both hospital and general practitioners. Because of limited resources and manpower, however, barium meal examinations remain the most accessible form of investigation for general practitioners. The relative merits of the two techniques are grossly distorted by Drs Sampson and Record. We believe that the use and interpretation of both are observer dependent. Lesions may be photographed or filmed during endoscopy, thus providing visual evidence as well as a written report. We doubt the relevance of "some aspects of function, hiatal hernias, and extrinsic mass lesions" to the management of dyspepsia. Barium contrast studies do not provide an ideal setting for measuring gastric emptying, evaluating gastro-oesophageal motility, and documenting gastro-oesophageal reflux. As for "extrinsic mass lesions," these are so rare as to be superfluous to this discussion. The comments on gastric cancer are both naive and dangerous. To suggest that double contrast barium meal examination can approach the diagnostic accuracy of gastroscopy with biopsy and cytology is totally unacceptable.

We agree that audit will prove a valuable tool for evaluating certain aspects of clinical practice, and we hope that such information will soon confirm both the diagnostic merits and the cost effectiveness of endoscopy for investigating dyspepsia.

W D W REES

C M BROWN

Department of Gastroenterology,

University of Manchester School of Medicine,

Hope Hospital,

Salford M6 8HD

1 Brown C, Rees WDW. Dyspepsia in general practice. Br Med $\mathrm{f}$ 1990;300:829-30. (31 March.)

2 Milewski PJ, Bancewicz J. Improving the results of treating gastric cancer. Br Med f 1989;299:278-9.

3 Fielding JWL. The consequences of overlooking serious diseases of the upper gastrointestinal tract. In: Colin-Jones D, Jones R, eds. Proceedings of a symposium on practical guidelines on the
management of dyspepsia. Macclesfield: Adelphi Communicamanagement of dyspepsia.

tion Limited, 1990: $28-33$.
4 Health and Public Policy Committee, American College of Physicians. Endoscopy in the evaluation of dyspepsia. Ann Intern Med 1985;102:266-9.

5 Macintyre IMC. Open access endoscopy for general practitioners. Practitioner 1988;232:348-51

6 Williams B, Ellingham JHM, Luckas M, Dain A, Wicks ACB Do young patients with dyspepsia need investigation? Lancel 1988;ii:1349-51.

7 De Dombal FT, Price AB, Thompson H, et al. The British Society of Gastroenterology early gastric cancer/dysplasia survey: an interim report. Gut 1990;31:115-20.

8 Sampson MA, Record C. Dyspepsia in general practice. Br Med f 1990;300:1137. (28 A pril.)

\section{Idiopathic dilated cardiomyopathy}

SIR,-Several comments made by $\mathrm{Dr}$ A L P Caforio and colleagues in their recent editorial on dilated cardiomyopathy are more controversial than might be appreciated generally.'

The authors state that "idiopathic cardiomyopathy is a chronic heart muscle disease." The evidence for that statement is almost non-existent. Studies on isolated heart muscle from patients with cardiomyopathy $y^{2}$ or heart failure ${ }^{3}$ show that developed tension under resting conditions, or in the presence of a high extracellular calcium con centration, is normal. The time to reach peak tension is extended but this is a feature of hypertrophy and not necessarily of heart failure. Many factors may limit the function of the heart as a pump including cell slippage, ventricular shape and geometry, orientation of muscle fibres, and particularly fibrosis. These factors will contribute to reducing the function of the heart as a pump even if contraction of the myocyte is normal. This argument does not exclude the possibility that initiating 